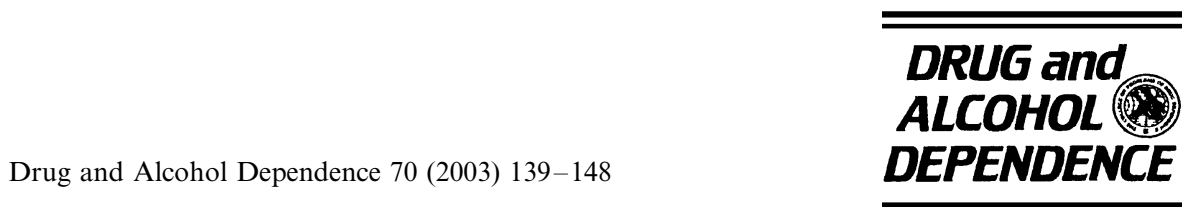

www.elsevier.com/locate/drugalcdep

\title{
Income distribution and risk of fatal drug overdose in New York City neighborhoods
}

\author{
Sandro Galea ${ }^{\mathrm{a}, \mathrm{b}, *}$, Jennifer Ahern ${ }^{\mathrm{a}}$, David Vlahov ${ }^{\mathrm{a}, \mathrm{b}}$, Phillip O. Coffin ${ }^{\mathrm{a}}$, \\ Crystal Fuller ${ }^{\mathrm{a}, \mathrm{b}}$, Andrew C. Leon ${ }^{\mathrm{c}}$, Kenneth Tardiff ${ }^{\mathrm{c}}$ \\ ${ }^{\text {a }}$ Center for Urban Epidemiologic Studies, New York Academy of Medicine, New York, NY 10024, USA \\ ${ }^{\mathrm{b}}$ Department of Epidemiology, Columbia University, New York, NY 10032, USA \\ ${ }^{\mathrm{c}}$ Department of Psychiatry, Weill Medical College of Cornell University, New York, NY 10021, USA
}

Received 18 July 2002; received in revised form 4 November 2002; accepted 4 November 2002

\begin{abstract}
Accidental drug overdose is a substantial cause of mortality for drug users. Neighborhood-level factors, such as income distribution, may be important determinants of overdose death independent of individual-level factors. We used data from the Office of the Chief Medical Examiner to identify all cases of accidental deaths in New York City (NYC) in 1996 and individual-level covariates. We used 1990 US Census data to calculate the neighborhood-level income distribution. This multi-level case-control study included 725 accidental overdose deaths (cases) and 453 accidental deaths due to other causes (controls) in 59 neighborhoods in NYC. Overdose deaths were more likely in neighborhoods with higher levels of drug use and with more unequal income distribution. In multi-level models, income maldistribution was significantly associated with risk of overdose independent of individual-level variables (age, race, and sex) and neighborhood-level variables (income, drug use, and racial composition). The odds of death due to drug overdose were 1.63-1.88 in neighborhoods in the least equitable decile compared with neighborhoods in the most equitable decile. Disinvestment in social and economic resources in unequal neighborhoods may explain this association. Public health interventions related to overdose risk should pay particular attention to highly unequal neighborhoods.
\end{abstract}

(C) 2002 Elsevier Science Ireland Ltd. All rights reserved.

Keywords: Drug overdose; Income inequality; Income distribution; Multi-level; Economics; Epidemiology

\section{Introduction}

Drug users are at substantially higher risk of morbidity and mortality than non-drug users (Cherubin and Sapira, 1993). Accidental drug overdoses are a major cause of mortality for drug users and, in many countries, are the leading cause of death in this group (Perucci et al., 1991; Oppenheimer et al., 1994; Frischer et al., 1997). More than two-third of drug users report a nonfatal drug overdose in their lifetime (Darke et al., 1996). Studies in the US show that drug users have a mortality rate 6.9 higher times than that in the general population;

* Corresponding author. Present address: Center for Urban Epidemiologic Studies, New York Academy of Medicine, 1216 Fifth Avenue, Room 556, New York, NY 10029, USA. Tel.: +1-212-8227378; fax: +1-212-876-6220

E-mail address: sgalea@nyam.org (S. Galea). a substantial proportion of that excess mortality is due to drug overdose (Joe and Simpson, 1987). Drug overdose decedents are typically male, long-time drug users, and in their late 20s and early 30s (Darke and Zador, 1996). Research has identified three types of factors that are associated with the likelihood of drug overdose: drug-related factors, user-related factors, and factors related to the drug using circumstance (Zinberg, 1986). Although most research into drug overdose has focused on the first two of these three categories (Darke and Zador, 1996), a small body of epidemiologic research has begun to explore the circumstances associated with drug overdose. For example, it has been shown that fatal drug overdose is more likely to occur soon after release from prison (Seymour et al., 2000). One ecologic study has demonstrated that neighborhood-level poverty accounts for a high proportion of the variance in drug overdose mortality rates between communities 
(Marzuk et al., 1997). This work suggests that contextual factors merit exploration as potential determinants of drug overdose.

In other areas, recent research has shown that neighborhood characteristics are important determinants of health even after accounting for differences in individual-level factors (Diez-Roux, 2001; Pickett and Pearl, 2001). For example, neighborhood socioeconomic status has been associated with mortality and coronary heart disease (Yen and Kaplan, 1999; Diez-Roux et al., 1997) and neighborhood conditions with physical function (Balfour and Kaplan, 2002). This research has led to a greater public health focus on identifying contextual or area-level factors that may shape the more familiar, proximal individual determinants of health (Power and Matthews, 1997; Kaplan, 1999). One of the area-level factors that has been subject to focused research and debate in the past decade is income distribution. Ecologic evidence has long suggested that countries with more egalitarian distribution of income have lower mortality rates (Rodgers, 1979). In the early 1990s, a series of publications spurred further interest in the role of income distribution as an area-level determinant of health (Wilkinson, 1992). Recent empiric evidence, although controversial, suggests that inequalities in income distribution contribute to health differentials between states and may contribute to some of the racial and socioeconomic disparities in health in the US (Lynch et al., 2001; Ross et al., 2000). The principal proponents of the hypothesized relation between income distribution and health suggest that perceived and actual inequities caused by the discrepancies in income distribution erode social trust and diminish the social capital that shapes societal wellbeing and individual health (Kawachi et al., 1997). Social capital is frequently conceptualized as the stock of social trust, norms, and networks that people in a particular area draw upon to solve common problems (Kawachi, 1999). Areas with more equitable income distribution and high social capital may be more likely to activate efficient systems that deal with emergent medical conditions or to care for those in acute distress.

Income distribution at the neighborhood level may be particularly important in the context of fatal drug overdose. For example, although drug overdoses are more likely to occur when an individual is using drugs in the company of others (Walsh, 1991; Zador et al., 1996), it has been shown that other persons present during a drug overdose seek medical help in fewer than half of all fatal overdoses (Manning et al., 1983; Zador et al., 1996). This reluctance to call for help may be based on fear of criminal prosecution or a general mistrust of authority suggesting erosion of social capital. It is then plausible that the risk of drug overdose may be higher in neighborhoods with more unequal income distribution and low social capital. Since accidental overdose fatal- ities are a subset of accidental deaths, we tested this hypothesis in a multi-level case-control study using data from New York City (NYC) for 1996. We hypothesized, a priori, that accidental mortality in neighborhoods with more unequal income distribution was more likely to be caused by drug overdose than by other accidental causes.

\section{Methods}

All cases of fatal accidents occurring in adults aged 15-64 in NYC during 1996 were identified through manual review of medical files at the Office of the Chief Medical Examiner of New York (OCME). OCME is responsible for assessing all deaths of persons believed to have died in an unnatural manner in NYC. Thus, all overdose deaths and deaths due to accidents in NYC would have been reviewed by the OCME and included in this chart extraction. The OCME investigators use the decedent's medical history, the circumstances and environment of the fatality, autopsy findings, and laboratory data in attributing cause of death and other criteria to each case reviewed. Deaths caused by accidental drug overdoses were considered cases in these analyses and deaths due to other accidents were considered controls. Accidental deaths included in these analyses were poisoning, asphyxiation, drowning, firearm deaths, stabbing, electrocutions, blunt trauma, crushing, falls, vehicular accidents, burns, explosions, environmental exposures, and other accidents. Deaths caused by human intent are not considered accidents by the OCME and were not included in these analyses. Data regarding age, gender, race/ethnicity, and residence were collected for all decedents from the OCME files. Decedents for whom the residence information was incomplete were excluded from these analyses.

NYC is divided into 59 residential community districts (CDs) by the Office of City Planning. These CDs delineate meaningful neighborhoods within NYC (Messner and Tardiff, 1986; Marzuk et al., 1997; Suecoff et al., 1999) and were used as neighborhood units in these analyses. These CDs will be referred to as neighborhoods hereafter. All cases and controls were classified by their neighborhood of residence. We used 1990 US Census data to obtain mean income and percent of black respondents in each neighborhood. All autopsied OCME cases undergo toxicological screening. We used proportion of accidental non-overdose decedents who were positive for any illegal drug other than marijuana to represent the level of drug use in a neighborhood.

We used two measures of income distribution: the Gini coefficient and the percent of total income earned by the lowest earning $70 \%$ of households. The two measures have previously been shown to be highly 
correlated (Kaplan et al., 1996; Kawachi et al., 1997; Kawachi and Kennedy, 1997). The Gini coefficient measures income distribution and extent of inequality. We used 1990 US Census data to calculate Gini coefficient for each neighborhood (Bureau of the Census, 1990). The Gini coefficient is shown by a Lorenz curve with the proportion of the population from richest to poorest represented on the $x$-axis and the proportion of the population's income on the $y$-axis. The Gini coefficient is the area between the diagonal line of no inequality and the concave line representing the income distribution in a particular population. Thus, a Gini coefficient of 0 denotes perfectly equitable income distribution, whereas a Gini coefficient of 1.0 represents maximal maldistribution. The percent of total income earned by the lowest earning $70 \%$ of households was estimated from 1990 US Census data by calculating the percent of the total income value in each neighborhood that was earned by the poorest $70 \%$ of households (Bureau of the Census, 1990). Therefore, neighborhoods with the percent of total income earned by the lowest earning $70 \%$ of households closer to $70 \%$ have more equitable income distribution.

We described the overdose and accident death rates by neighborhood and used chi-square tests and $t$-tests as appropriate to test for differences between demographic factors in cases and controls. Crude mortality rates were calculated for each neighborhood as the number of fatal drug overdoses and the number of fatal accidents per 100,000 residents per neighborhood. We analyzed the ecologic relation between both indices of income distribution (i.e. Gini coefficient and percent of total income earned by lowest earning $70 \%$ of households) and overdose and accident mortality rates at the neighborhood level. Generalized additive models best described the relation between the two measures of income distribution and the two outcomes of interest (Hastie and Tibshirani, 1990). We used two-tailed ANOVA to test for improved model fit $(P<0.05)$. Spline models provided the best-fit in describing these relations.

We used logistic regression to test the bivariate relations between the covariates of interest and the likelihood of overdose fatality compared with accident fatality. The linearity of the relation between each covariate and outcome was tested using differences in $\log$-likelihood ratios $(P<0.1)$. Evidence of a nonlinear relation between mean neighborhood income and the outcome was found. The relation between mean neighborhood income and the risk of drug overdose death was best described by a quadratic income term and neighborhood income was subsequently modeled in quadratic form. We used generalized estimating equations to fit separate multi-level multivariable models that assessed the relation between each measure of income distribution and the likelihood of fatal drug overdose (Zeger and Liang, 1986). Multivariable models included neighborhood-level variables (income in quadratic form, neighborhood racial composition, neighborhood drug use, and income distribution) and individuallevel variables (age, race, and sex). To assess the magnitude of the relation between income distribution and likelihood of drug overdose, we calculated the odds ratios for percentiles of both measures of income distribution (for the range of Gini coefficients and proportion income earned by the lowest earning $70 \%$ of households in the data set) setting the midpoint of the lowest decile as the referent.

\section{Results}

Table 1 presents baseline characteristics of the study population. Overall, 725 overdose deaths and 453 accident deaths were included in the analyses. Mean age was 40.4 (S.D. $=8.7)$ and $40.6($ S.D. $=13.5)$ among overdose and accident deaths, respectively. $76.3 \%$ of overdose deaths and $78.8 \%$ of accident deaths were male. Overdose decedents were more likely to be black (37.2\%) compared with accident deaths (33.5\%). On average, neighborhood per capita income was similar in both groups; mean per capita annual income in overdose decedents was $\$ 14,400$ and in accident decedents was $\$ 14,600$. Neighborhood racial composition was similar in both the groups. On average, overdose deaths were more often in neighborhoods with a higher prevalence of drug use ( $29.4 \%$ vs. $24.1 \%$ for accident decedents), higher Gini coefficient $(0.452$ vs. 0.443 for accident decedents), and lower proportion of income earned by the lowest earning $70 \%$ of households $(37.9 \%$ vs. $38.9 \%$ for accident decedents). The median number of overdose decedents in a neighborhood was 10 (range: 0-33) and median number of accident decedents was 7 (range: $1-$ 17). Two hundred and thirty-four decedents were excluded from the analysis due to missing residence information. These decedents did not differ appreciably in demographic information from the decedents who were included. In this data, Gini coefficients ranged from 0.354 to 0.506 and percent of total income earned by the lowest earning $70 \%$ of households ranged from $47.2 \%$ to $32.9 \%$ (most equitable to least equitable neighborhoods for both measures). Gini coefficient and percent of total income earned by the lowest earning $70 \%$ of households were highly correlated $(r=-0.958$, $P=<0.0001)$.

Fig. 1 shows the best-fit model describing the ecologic relations of Gini coefficient with neighborhood overdose and accident fatality rates. A spline model shows that neighborhoods with large Gini coefficients had higher rates of overdose fatality rates compared with neighborhoods with low Gini coefficients. There was a small increase in accident fatality rate among neighborhoods 
Table 1

Demographic and neighborhood characteristics of overdose and accident deaths (age: 15-64), NYC, 1996

\begin{tabular}{|c|c|c|c|c|c|}
\hline \multirow[t]{2}{*}{ Characteristic } & \multicolumn{2}{|c|}{ Overdose deaths $N=725$} & \multicolumn{2}{|c|}{ Accident deaths $N=453$} & \multirow[t]{2}{*}{$P$-value* } \\
\hline & $N$ & $\%$ & $N$ & $\%$ & \\
\hline \multicolumn{6}{|l|}{ Gender } \\
\hline Male & 553 & 76.3 & 357 & 78.8 & 0.31 \\
\hline Female & 172 & 23.7 & 96 & 21.2 & \\
\hline \multicolumn{6}{|l|}{ Racelethnicity } \\
\hline White & 233 & 32.1 & 135 & 29.8 & $<0.0001$ \\
\hline Black & 270 & 37.2 & 152 & 33.5 & \\
\hline Hispanic & 215 & 29.7 & 129 & 28.5 & \\
\hline \multirow[t]{2}{*}{ Other } & 7 & 1.0 & 37 & 8.2 & \\
\hline & Mean & S.D. & Mean & S.D. & \\
\hline Age & 40.4 & 8.7 & 40.6 & 13.5 & 0.69 \\
\hline Per capita income $(\$)^{\mathrm{a}}$ & 14400 & 10200 & 14600 & 9000 & 0.77 \\
\hline Percent black residents & 31.2 & 28.1 & 29.5 & 26.9 & 0.30 \\
\hline Percent of accidents with drugs detected & 29.4 & 20.0 & 22.6 & 21.6 & $<0.0001$ \\
\hline Gini coefficient ${ }^{\mathrm{b}}$ & 0.452 & 0.036 & 0.443 & 0.038 & $<0.0001$ \\
\hline Percent income earned by lowest earning $70 \%$ of households & 37.9 & 3.4 & 38.9 & 3.5 & $<0.0001$ \\
\hline
\end{tabular}

a Mean neighborhood income from 1990 US Census data.

b Measure of income distribution; ranges from 0 (perfectly equitable income distribution) to 1 (maximal maldistribution).

* Chi-square test for categorical variables and $t$-test for continuous variables.

with higher Gini coefficients compared with neighborhoods with lower Gini coefficients. Fig. 2 shows the best-fit model describing the ecologic relation between percent of total income earned by the lowest $70 \%$ of households and overdose and accident mortality rates. Neighborhoods with a lower percent of total income earned by the lowest $70 \%$ of earners had substantially higher overdose death rates than did neighborhoods with more equitable income distribution. There was a small increase in accident fatality rates among neighborhoods with more inequitable income distribution compared with neighborhoods with more equitable income

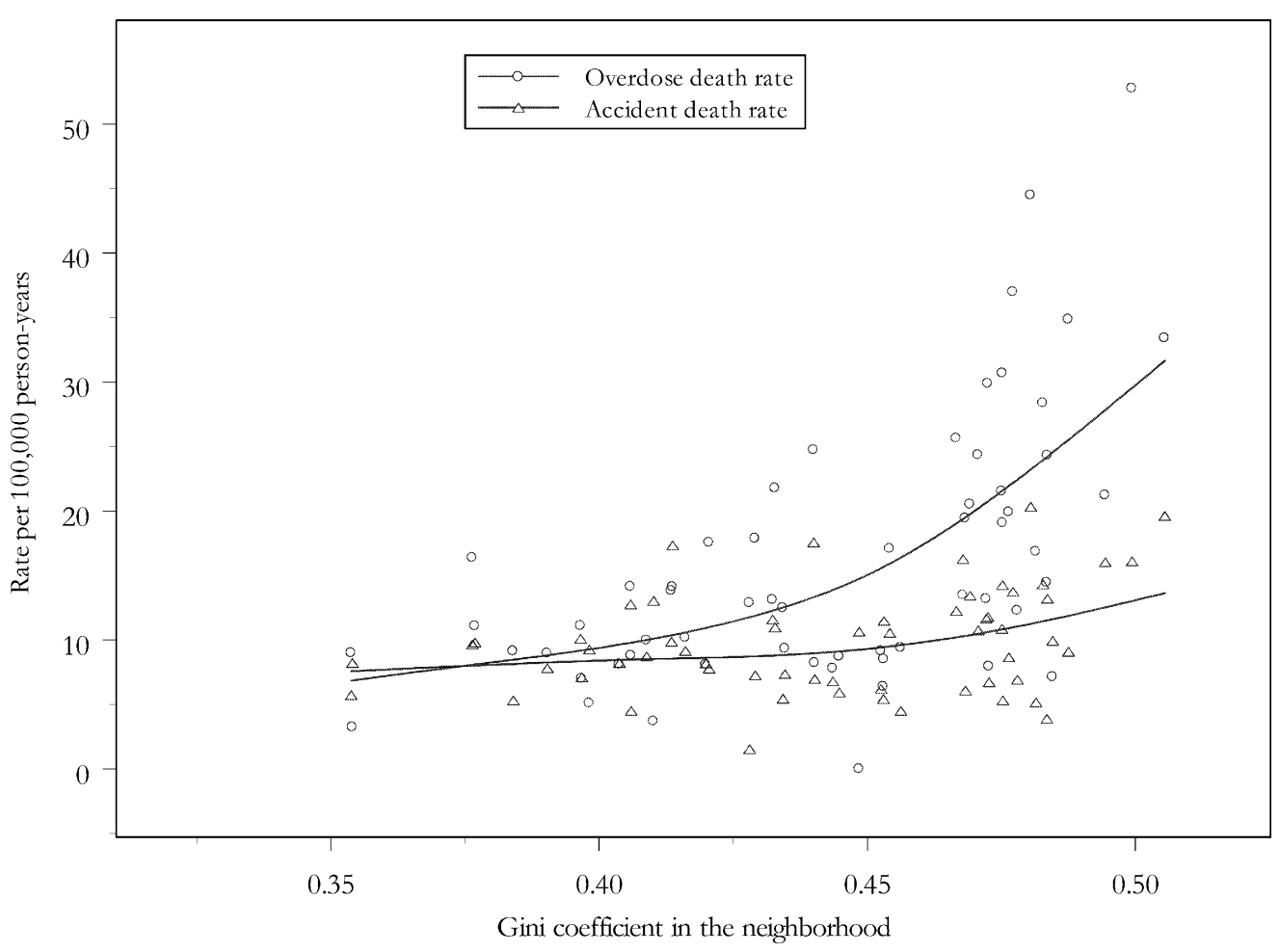

Fig. 1. Overdose and accident death rates by Gini coefficient in the neighborhood. Symbols show results for individual neighborhoods. 


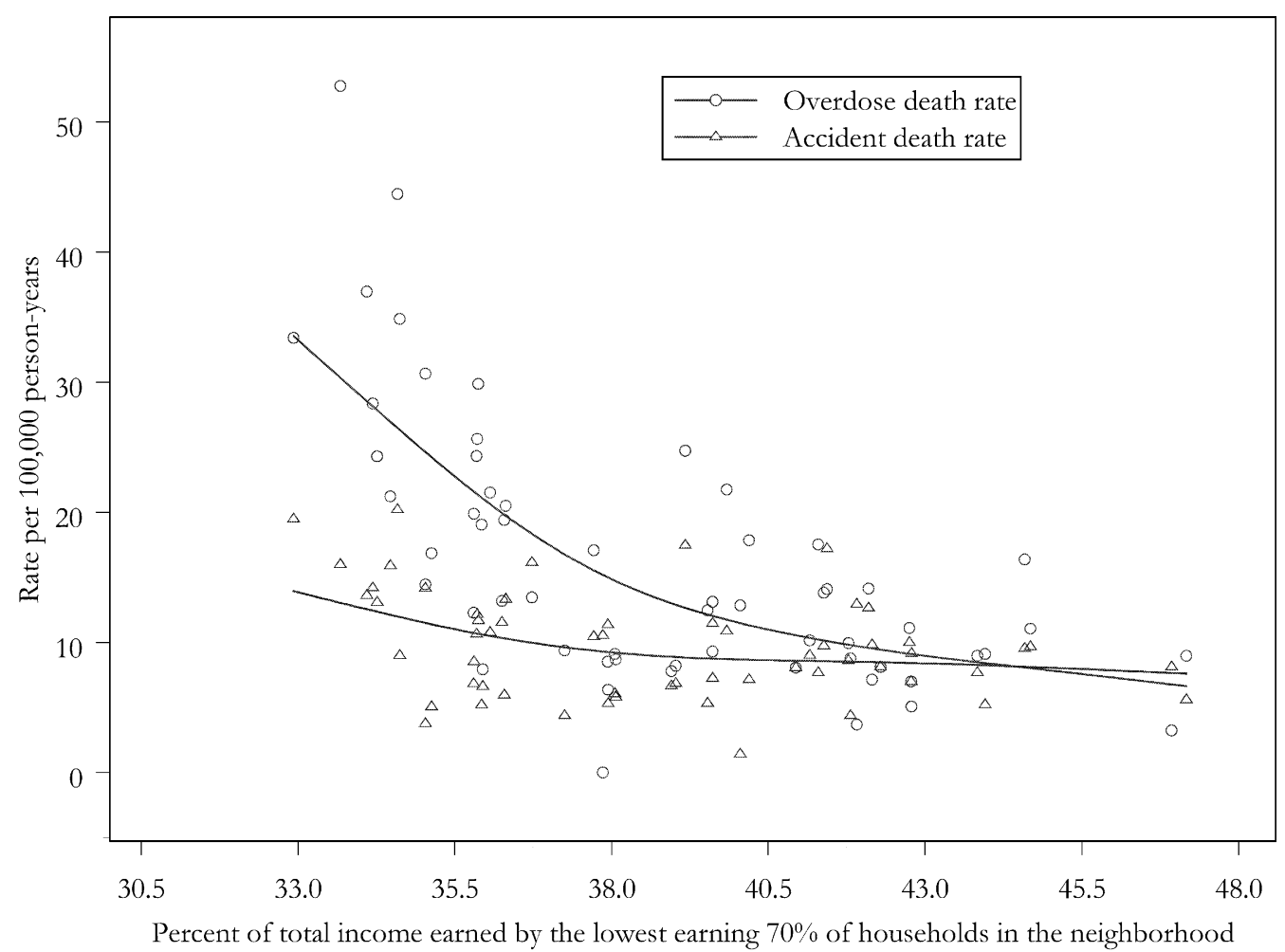

Fig. 2. Overdose and accident death rates by percent of total income earned by the lowest earning $70 \%$ of households. Symbols show results for individual neighborhoods.

distribution. Both overdose mortality best-fit models suggest a threshold effect, with the slope of the line describing the relation between index of income distribution and overdose mortality changing above Gini coefficient of 0.45 and below $39 \%$ of income earned by the lowest $70 \%$ of households.

Table 2 shows the unadjusted relations between individual- and neighborhood-level covariates of inter- est and likelihood of overdose mortality in logistic regression models. The quadratic form of income was significantly associated with likelihood of drug overdose ( $P=0.01$ for both terms); lower neighborhood income was associated with drug overdose. A higher level of neighborhood drug use was significantly associated with a greater likelihood of drug overdose fatality $(P<$ 0.0001). Less equitable income distribution as measured

Table 2

Unadjusted relations between individual- and neighborhood-level covariates and overdose mortality, NYC, 1996

\begin{tabular}{|c|c|c|c|}
\hline Characteristic & Beta & Standard error (SE) & $P$-value \\
\hline Gini coefficient ${ }^{\mathrm{a}}$ & 7.0926 & 1.6977 & $<0.0001$ \\
\hline Percent income earned by lowest earning $70 \%$ of households & -0.0858 & 0.0174 & $<0.0001$ \\
\hline Age & 0.0022 & 0.0055 & 0.69 \\
\hline Male $^{\mathrm{b}}$ & 0.1298 & 0.1448 & 0.37 \\
\hline Black $^{\mathrm{c}}$ & 0.0084 & 0.1430 & 0.95 \\
\hline Hispanic $^{c}$ & 0.0730 & 0.1481 & 0.62 \\
\hline Other race ${ }^{\mathrm{c}}$ & 2.2034 & 0.3878 & $<0.0001$ \\
\hline Income $^{\mathrm{d}}$ & 0.6095 & 0.2482 & 0.01 \\
\hline Income $^{2}$ & 0.1099 & 0.0425 & 0.01 \\
\hline Percent black residents & 0.0018 & 0.0028 & 0.53 \\
\hline Percent drugs detected among accidents & 0.0151 & 0.0036 & $<0.0001$ \\
\hline
\end{tabular}

\footnotetext{
a Measure of income distribution; ranges from 0 (perfectly equitable income distribution) to 1 (maximal maldistribution).

b Female referent.

c White race referent.

${ }^{d}$ Mean neighborhood income from 1990 US Census data.
} 
Table 3

Multi-level models of the relation between income inequality indices and overdose mortality, NYC, 1996

\begin{tabular}{|c|c|c|c|c|c|c|}
\hline \multirow[t]{2}{*}{ Characteristic } & \multicolumn{3}{|c|}{ Gini coefficient ${ }^{\mathrm{a}}$} & \multicolumn{3}{|c|}{ Percent of total income earned by lowest $70 \%$ of households } \\
\hline & Beta & SE & $P$-value & Beta & SE & $P$-value \\
\hline Inequality measure & 4.0130 & 1.8074 & 0.03 & -0.0576 & 0.0200 & 0.004 \\
\hline Age & -0.0064 & 0.0072 & 0.37 & -0.0066 & 0.0071 & 0.35 \\
\hline Male ${ }^{\mathrm{b}}$ & -0.1120 & 0.1602 & 0.48 & -0.1096 & 0.1598 & 0.49 \\
\hline Black $^{\mathrm{c}}$ & -0.1890 & 0.1779 & 0.29 & -0.2003 & 0.1784 & 0.2614 \\
\hline Hispanic $^{c}$ & -0.2822 & 0.1632 & 0.08 & -0.3008 & 0.1649 & 0.0682 \\
\hline Other ${ }^{\mathrm{c}}$ & -2.1937 & 0.3980 & $<0.0001$ & -2.1891 & 0.3969 & $<0.0001$ \\
\hline Income $^{\mathrm{d}}$ & -0.3134 & 0.2369 & 0.19 & -0.2065 & 0.2332 & 0.38 \\
\hline Income $^{2}$ & 0.0545 & 0.0358 & 0.13 & 0.0366 & 0.0352 & 0.30 \\
\hline Percent black residents & -0.0008 & 0.0028 & 0.78 & -0.0002 & 0.0026 & 0.93 \\
\hline Percent drugs detected among accidents & 0.0105 & 0.0038 & 0.02 & 0.0095 & 0.0039 & 0.02 \\
\hline
\end{tabular}

${ }^{\text {a }}$ Measure of income distribution; ranges from 0 (perfectly equitable income distribution) to 1 (maximal maldistribution).

b Female referent.

c White race referent.

d Mean neighborhood income from 1990 US Census data.

by Gini coefficient $(P<0.0001)$ and lower percent income earned by the lowest $70 \%$ of households $(P<$ $0.0001)$ were both associated with a greater likelihood of drug overdose mortality.

Table 3 presents two models that describe the adjusted relation between the two measures of income distribution and likelihood of drug overdose. In separate multivariable models, Gini coefficient $(P=0.03)$ and percent of total income earned by the lowest $70 \%$ of households $(P=0.004)$ were significant predictors of higher likelihood of drug overdose in NYC neighborhoods.

Fig. 3 presents the relative odds ratios for overdose death compared with death due to other accidental causes by percentiles of Gini coefficient. Compared with the midpoint of the lowest Gini decile in neighborhoods

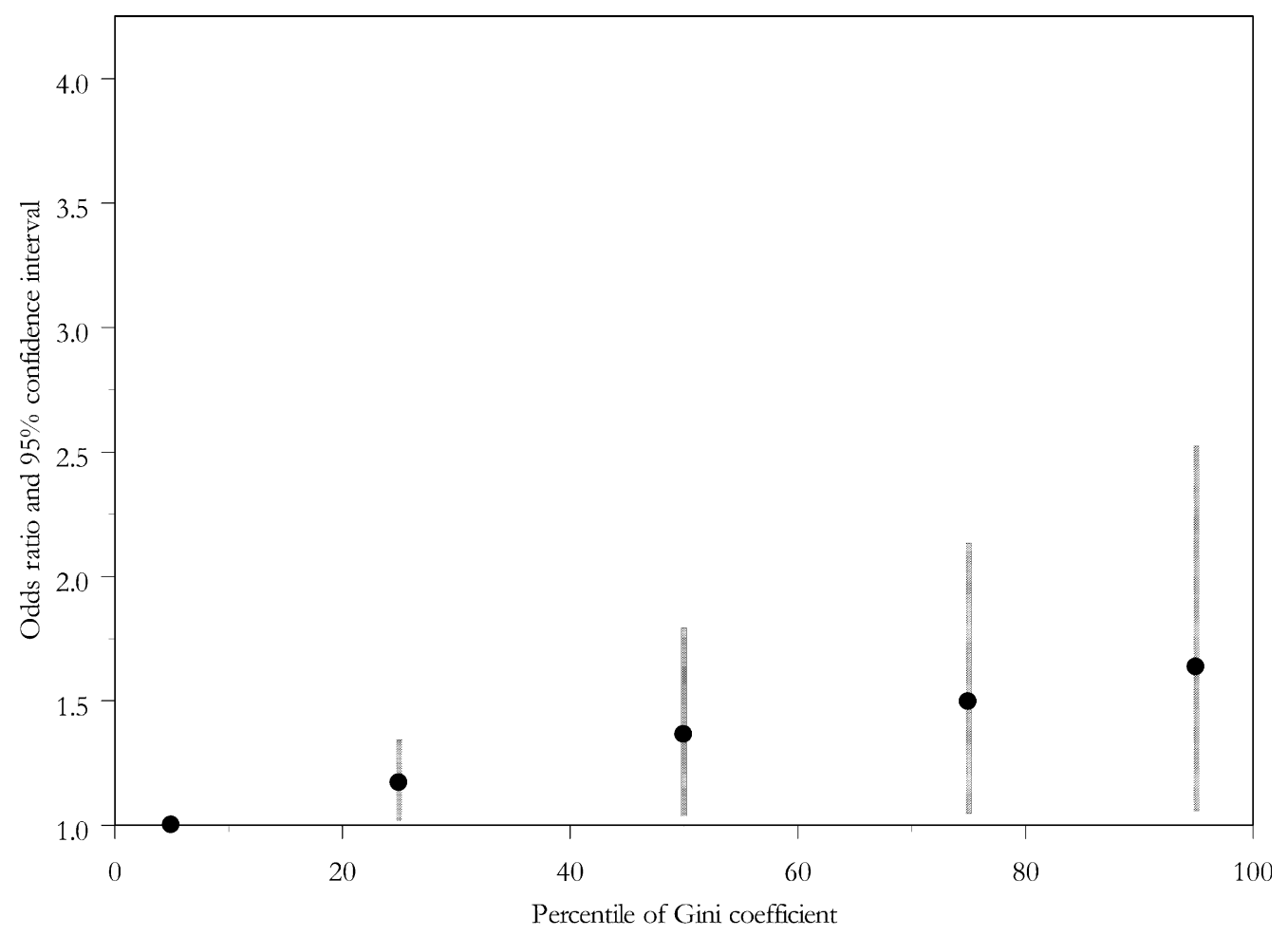

Fig. 3. Odds ratios for overdose deaths by percentiles of the Gini coefficient. 


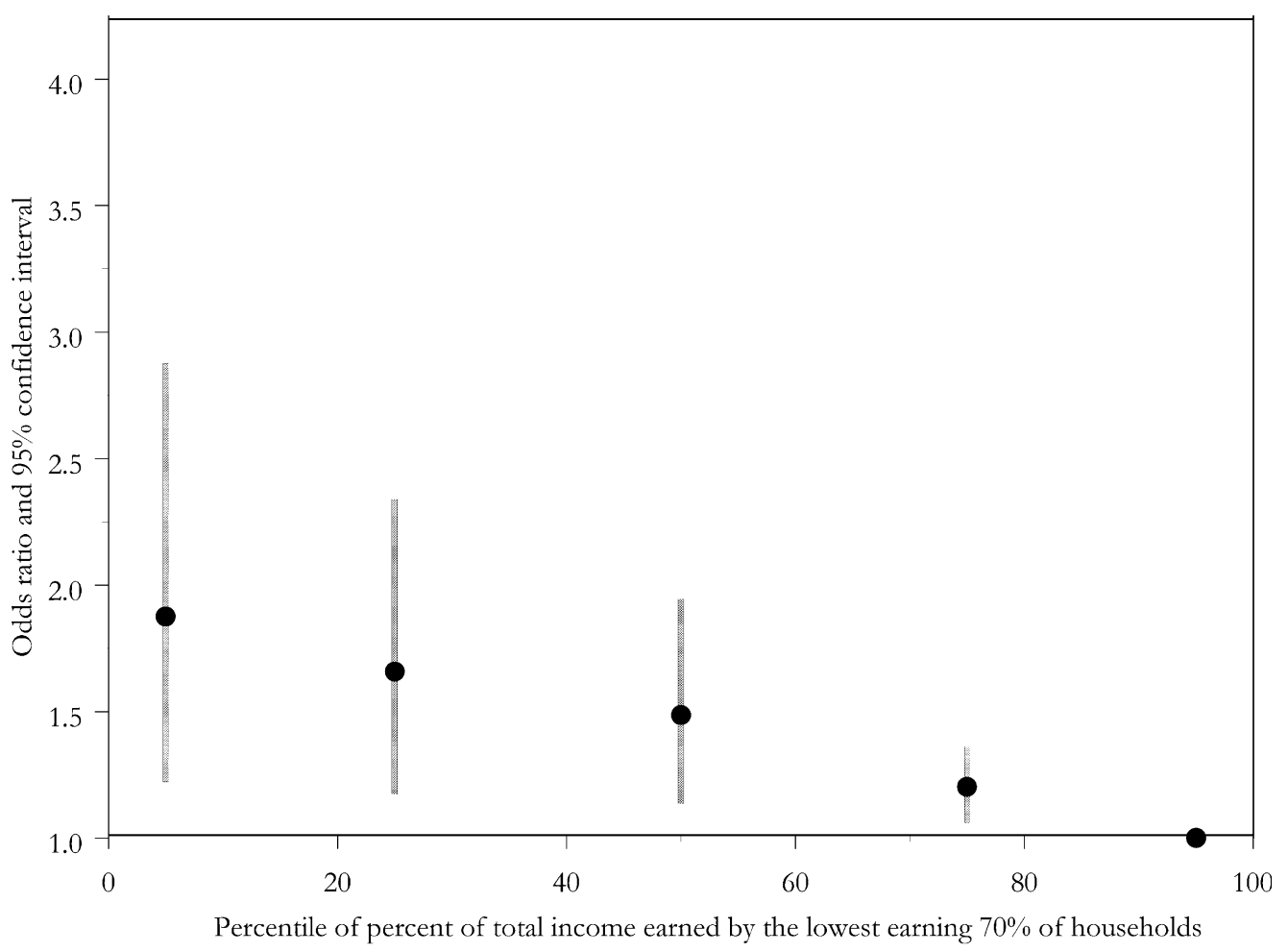

Fig. 4. Odds ratios for overdose death by percentiles of percent of total income earned by the lowest earning $70 \%$ of households.

in the 50th percentile of Gini distribution ratio, the relative odds of death due to drug overdose were 1.36 (95\% confidence interval, $\mathrm{CI}=1.04,1.79)$ and in neighborhoods in the top decile the relative odds were 1.63 $(95 \% \mathrm{CI}=1.06,2.52)$. Fig. 4 presents the relative odds ratios for overdose death by percentiles of percent of total income earned by the lowest earning $70 \%$ of households. Compared with the midpoint of the most equitable income decile, the relative odds of death due to drug overdose in neighborhoods in the 50th decile were $1.49(95 \% \mathrm{CI}=1.13,1.95)$ and in neighborhoods in the least equitable decile the relative odds were $1.88(95 \%$ $\mathrm{CI}=1.22,2.88)$.

\section{Discussion}

In a multi-level case-control study, we found that in neighborhoods with more unequal income distribution, drug overdose was a more likely cause of accidental death than other causes. The relation between income distribution and risk of drug overdose fatality was present in models that adjusted for individual- and neighborhood-level covariates including demographics, neighborhood income, racial composition of neighborhood, and level of drug use in the neighborhood. The relative odds of death due to drug overdose were $1.63-$ 1.88 in neighborhoods in the top decile of income maldistribution compared with the most equitable neighborhoods.

The relation between income distribution and mortality has been controversial (Wagstaff and van Doorslaer, 2000; Mackenbach, 2002). Although studies in the early 1990s demonstrated this relation in a number of ecologic studies, later work suggested that this effect was due to the relation between income (Osler et al., 2002) or education (Muller, 2002) and mortality. Other multilevel studies failed to demonstrate an association between area-level income distribution and mortality (Fiscella and Franks, 1997). Our data suggest that NYC neighborhoods with more unequal income distribution were more likely to have overdose as a cause of accidental death than other causes. This relation is robust across different indices of income inequality and in adjusted models that account for potential individual and area-level confounders. Conceptually, the principal hypotheses that explain the relation between unequal income distribution and health have two components. First, unequal income distribution may be associated with policies and processes that result in under-investment in human health and social resources. Loss of social capital in these circumstances has been considered as a mediator of the observed relations between income distribution and health. Second, unequal income distribution may be a direct stressor on persons who perceive their relatively low position in the 
economic hierarchy (Lynch and Kaplan, 1997). In the context of NYC neighborhoods, the impact of the inequality in income distribution on overdose is plausibly mediated both by more limited resources being available to assist those in acute need of life-saving assistance and by greater individual vulnerability to poor health. Limited access to ongoing health care (including drug rehabilitation or counseling), longer paramedic response times, greater mistrust of authority and a reluctance to call for help, and different illicit drug formulations in more unequal neighborhoods could all explain the observed associations. These explanations would be consistent with the hypothesized relative deterioration in social and economic assets occurring in more unequal neighborhoods. The persistence of the relation between unequal income distribution and likelihood of overdose after adjusting for neighborhoodlevel drug use suggests that factors in unequal neighborhoods beyond the availability of drugs are responsible for the observed associations.

One critique of cross-sectional associations between income distribution and mortality is the lack of plausible biologic pathways that explain an instantaneous relation between income distribution and mortality. Individuallevel studies have demonstrated that the cumulative effects of social circumstances over a lifetime are important socioeconomic predictors of mortality (Judge et al., 1998; Hart et al., 1998). However, causes of death such as accidents and violence are not usually the outcome of long-term biological process and as such are plausibly related to social disruption in the shortterm (Smith, 1996). The relation between income distribution and mortality has been shown to be particularly strong for causes of death such as homicide and mortality among young people (Kennedy et al., 1996). Therefore, the association between income distribution and risk of drug overdose may represent processes that are happening in the relative short-term and are amenable both to early detection and potentially to public health intervention. The observation of a threshold effect, whereby neighborhoods with inequality of income distribution above a certain measurable level had appreciably higher overdose mortality rates, may be a useful guide to the allocation of public health resources and intervention effort.

Our observations are limited by the nature of our data. We used data from OCME files that enumerate all accidental deaths in NYC. The NYC OCME endeavors to apply uniform guidelines to its reporting about all cases to ensure consistency of determination of causes of death (Tardiff et al., 1996). This suggests that data analyzed are an accurate representation of the causes of death in NYC during 1996. All unexpected deaths should be reported to the OCME and, as such, we expect that case finding included in this study was complete. Although we controlled the available relevant individual- and neighborhood-level variables, we did not have individual measures of socioeconomic status available. It is possible that residual cross-level confounding or confounding by covariates not considered here could explain some of the observed relation between income distribution and likelihood of overdose mortality. Consistent with previous research (Marzuk et al., 1997), we used CDs as proxies for neighborhoods in NYC. Definition of relevant neighborhood units is challenging and these units, while large, are probably more meaningful analytic units than either census tracts or zip codes, the most commonly used units of analysis in the study of neighborhood-level effects (Messner and Tardiff, 1986; Diez-Roux, 2001). Use of smaller neighborhood-level units, however, may have allowed the measure of small area characteristics that may mediate the observed relation. Finally, we used census data from the beginning of the decade and it is difficult to know how well this information represents conditions of neighborhoods in NYC in 1996 and whether any changes may account for some of the observed associations.

Notwithstanding these limitations, we demonstrated an association between income maldistribution and risk of drug overdose death that is robust across indices of inequality in models adjusting for individual- and neighborhood-level covariates. These data suggest that neighborhood factors play a role in determining the risk of overdose mortality and could have implications for public health efforts aimed at reducing this cause of death. Overdose prevention interventions are almost all focused on the individual drug user (Lenton and Hargreaves, 2000; Oliver et al., 2001). Both educational interventions and harm reduction intervention approaches focus on drug users' cognitive and behavioral processes. Although these factors are undoubtedly important, these data suggest that structural factors are important determinants of fatal overdose independent of individual-level factors. If disinvestment in social and economic resources in unequal neighborhoods is associated with greater mistrust of authority, slower emergency medical service response time, and more limited availability of regular medical care, interventions that focus exclusively on the drug user will fail unless these structural factors are also addressed. Our findings suggest that public health interventions related to overdose risk should pay particular attention to highly unequal neighborhoods. These findings may be a useful guide to public policy decisions about the targeting of treatment resources or for improving emergency medical system response where overdoses occur. Further research should investigate specific pathways that explain the relation between neighborhood-level inequalities and risk of overdose. 


\section{Acknowledgements}

This work was partly funded by grant DA-06534 from the National Institute on Drug Abuse.

\section{References}

Balfour, J.L., Kaplan, G.A., 2002. Neighborhood environment and loss of physical function in older adults: evidence from the Alameda County Study. Am. J. Epidemiol. 155, $507-515$.

Bureau of the Census, 1990. Census summary tape, file 3A (STF 3A). US Department of Commerce, Washington, DC. http://www.census.gov/ftp/pub/populatin/www/estimates/co_crh.html.

Cherubin, C.E., Sapira, J.D., 1993. The medical complications of drug addiction and the medical assessment of the intravenous drug user: 25 years later. Ann. Intern. Med. 119, 1017-1028.

Darke, S., Zador, D., 1996. Fatal heroin overdose: a review. Addiction 91, 1765-1772.

Darke, S., Ross, J., Hall, W., 1996. Overdose among heroin users in Sydney, Australia. I. Prevalence and correlates of non-fatal overdose. Addiction 91, 405-411.

Diez-Roux, A.V., 2001. Investigating neighborhood and area effects on health. Am. J. Public Health 91, 1783-1789.

Diez-Roux, A.V., Nieto, F.J., Muntaner, C., Tyroler, H.A., Comstock, G.W., Shahar, E., Cooper, L.S., Watson, R.L., Szklo, M., 1997. Neighborhood environments and coronary heart disease: a multilevel analysis. Am. J. Epidemiol. 146, 48-63.

Fiscella, K., Franks, P., 1997. Poverty or income inequality as predictor of mortality: longitudinal cohort study. Br. Med. J. $314,1724-1728$.

Frischer, M., Goldberg, D., Rahman, M., Berney, L., 1997. Mortality and survival among a cohort of drug injectors in Glasgow, 19821994. Addiction 92, 419-427.

Hart, C.L., Smith, G.D., Blane, D., 1998. Inequalities in mortality by social class measured at three stages of the lifecourse. Am. J. Public Health 88, 471-474.

Hastie, T., Tibshirani, R., 1990. Generalized Additive Models. Monographs on Statistics and Applied Probability Series. Chapman \& Hall, New York, p. 43.

Joe, G.W., Simpson, D.D., 1987. Mortality rates among opioid addicts in a longitudinal study. Am. J. Public Hlth. 77, 347-348.

Judge, K., Mulligan, J.A., Benzeval, M., 1998. Income inequality and population health. Soc. Sci. Med. 46, 567-579.

Kaplan, G., 1999. What is the role of the social environment in understanding inequalities in health? Ann. NY Acad. Sci. 896, $116-119$.

Kaplan, G.A., Pamuk, E.R., Lynch, J.W., Cohen, R.D., Balfour, J.L., 1996. Inequality in income and mortality in the United States: analysis of mortality and potential pathways. Br. Med. J. 312, 9991003.

Kawachi, I., 1999. Social capital and community effects on population and individual health. Ann. NY Acad. Sci. 896, 120-130.

Kawachi, I., Kennedy, B.P., 1997. The relationship of income inequality to mortality: does the choice of indicator matter? Soc. Sci. Med. $45,1121-1127$

Kawachi, I., Kennedy, B.P., Lochner, K., Prothrow-Stith, D., 1997. Social capital, income inequality, and mortality. Am. J. Public Hlth. 87, 1491-1498.

Kennedy, B.P., Kawachi, I., Prothrow-Stith, D., 1996. Income distribution and mortality: cross-sectional ecological study of the Robin Hood index in the United States. Br. Med. J. 312, 10041007.
Lenton, S.R., Hargreaves, K.M., 2000. Should we conduct a trial of distributing naloxone to heroin users for peer administration to prevent fatal overdose? Med. J. Aust. 173, 260-263.

Lynch, J.W., Kaplan, G.A., 1997. Understanding how inequality in the distribution of income affects health. J. Hlth. Psychol. 2, 297-314.

Lynch, J., Smith, G.D., Hillemeier, M., Shaw, M., Raghunathan, T., Kaplan, G., 2001. Income inequality, the psychosocial environment and health: comparisons of wealthy nations. Lancet 358, 12851287.

Mackenbach, J.P., 2002. Income inequality and population health. Br. Med. J. 324, 1-2.

Manning, F.J., Ingraham, L.H., DeRouin, E.M., Vaughn, M.S., Kukura, F.C., St Michel, G.R., 1983. Drug overdoses among US soldiers in Europe, 1978-1979: psychological autopsies following deaths and near-deaths. Int. J. Addict. 18, 153-166.

Marzuk, P.K., Tardiff, K., Leon, A.C., Hirsch, C.S., Stajic, M., Portera, L., Hartwell, N., 1997. Poverty and fatal accidental drug overdoses of cocaine and opiates in New York City: an ecological study. Am. J. Drug Alcohol Abuse 23, 221-228.

Messner, S.F., Tardiff, K., 1986. Economic inequality and levels of homicide: an analysis of urban neighborhoods. Criminology 24, 297-317.

Muller, A., 2002. Education, income inequality, and mortality: a multiple regression analysis. Br. Med. J. 324, 23-25.

Oliver, P., Rowse, G., Keen, J., Forrest, R., 2001. Snoring prior to fatal opiate overdose: an intervention opportunity? Addiction 96, 652.

Oppenheimer, E., Tobutt, C., Taylor, C., Andrew, T., 1994. Death and survival in a cohort of heroin addicts from London clinics: a 22 year follow-up study. Addiction 89, 1299-1308.

Osler, M., Prescott, E., Gronbaek, M., Christensen, U., Due, P., Engholm, G., 2002. Income inequality, individual income, and mortality in Danish adults: analysis of pooled data from two cohort studies. Br. Med. J. 324, 13-16.

Perucci, C.A., Davoli, M., Rapiti, E., Bargagli, A.M., D’Ippoliti, D., Forastiere, F., Abeni, D., 1991. Mortality of intravenous drug users in Rome: a cohort study. Am. J. Public Hlth. 81, $1307-1310$.

Pickett, K.E., Pearl, K., 2001. Multi-level analyses of neighborhood socioeconomic context and health outcomes: a critical review. J. Epidemiol. Community Hlth. 55, 111-122.

Power, C., Matthews, S., 1997. Origins of health inequalities in a national population sample. Lancet 350, 1584-1589.

Rodgers, G.B., 1979. Income and inequality as determinants of mortality: an international cross-section analysis. Popul. Stud. 31, $182-191$.

Ross, N.A., Wolfson, M.C., Dunn, J.R., Berthelot, J.-M., Kaplan, G.A., Lynch, J.W., 2000. Relation between income inequality and mortality in Canada and in the United States: cross-sectional assessment using census data and vital statistics. Br. Med. J. 320, $898-902$.

Seymour, A., Oliver, J.S., Black, M., 2000. Drug-related deaths among recently released prisoners in the Strathclyde Region of Scotland. J. Forensic Sci. 45, 649-654.

Smith, G.D., 1996. Income inequality and mortality: why are they related? Br. Med. J. 312, 987-988.

Suecoff, S.A., Avner, J.R., Chou, K.J., Crain, E.F., 1999. A comparison of New York City playground hazards in high- and low-income areas. Arch. Pediatr. Adolesc. Med. 153, $363-366$.

Tardiff, K., Marzuk, P.M., Leon, A.C., Portera, L., 1996. Accidental fatal drug overdoses in New York City: 1990-1992. Am. J. Drug Alcohol Abuse 22, 135-146.

Wagstaff, A., van Doorslaer, E., 2000. Income inequality and health: what does the literature tell us? Annu. Rev. Public Hlth. 21, 543567. 
Walsh, R.A., 1991. Opioid drug accidental deaths in the Newcastle area of New South Wales, 1970-1987. Drug Alcohol Rev. 19, 7983.

Wilkinson, R.G., 1992. Income distribution and life expectancy. Br. Med. J. 304, 165-168.

Yen, I.H., Kaplan, G.A., 1999. Neighborhood social environment and risk of death: multi-level evidence from the Alameda County Study. Am. J. Epidemiol. 149, $898-907$.
Zador, D., Sunjic, S., Darke, S., 1996. Heroin-related deaths in New South Wales, 1992: toxicologic findings and circumstances. Med. J. Aust. 164, 204-207.

Zeger, S.L., Liang, K.-Y., 1986. Longitudinal data analysis for discrete and continuous outcomes. Biometrics 42, 121-130.

Zinberg, N.E., 1986. Drug, Set, and Setting: The Basis for Controlled Intoxicant Use. Yale University Press, New Haven, CT. 